
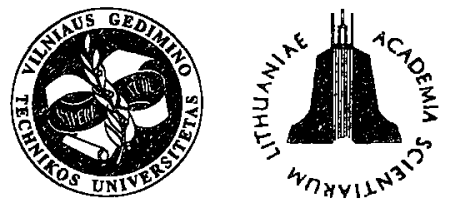

ISSN 1648-4142 TRANSPORT

http:/www.vtu.lt/english/editions

TRANSPORT - 2003, Vol XVIII, No 1, 13-17

\title{
INVESTIGATION OF INFORMATIONAL TECHNOLOGIES IN FREIGHT FORWARDING
}

\author{
Nijolé Batarliené \\ Dept of Transport Management, Vilnius Gediminas Technical University, \\ Plytines g. 27, LT-2040 Vilnius, Lithuania.E-mail:nijbat@ti.vtu.lt
}

Received 20021214 ; accepted 20021223

\begin{abstract}
This article examines types of informational technologies application problems, shows their scheme, observes basic data structures of technological problems, principles and methods of modeling these structures. It is noted that the solution of transport technology problems is based on the improvement of technological supply, the rational usage of informational modeling methodology of the whole transportation process. There are informational search and presentation computerized technologies when indexation and coding system are used to create them. As an example, dangerous freight forwarding resolution codification is shown, which is used for searching the most important resolutions and for their presentation to all the dangerous freight-forwarding participants. The present informational search and presentation programs that improve the possibilities of the presented search are observed as well.
\end{abstract}

Keywords: informational technologies; transport; regulations; codification system; dangerous goods; search system.

\section{Introduction}

As a planning and management object transport is a complicated system, which state is defined by the number of external and internal factors. That's why it is necessary to apply informational technologies and to choose certain organizational peculiarities of transportation for each different transport mode.

While preparing transport development scheme of the republic as well as extending transport development program, it is necessary to try the newest achievements of the informational technology application and mathematical modeling sphere. The basis of the new transport development strategy should become journey and fright formation as well as the creation of criteria distribution models.

In this article it is attempted to examine briefly the peculiarities of modeling characteristics of transport system, structures of models, to present the possibilities of application of informational technologies and their importance. The modeling methods of the basic data, the examples of application of these methods allow to understand more easily the solution of freight forwarding problem applying mathematical models of informational processes.

\section{Types of Transport Tasks, Using Informational Tech- nologies}

Having examined the basic transport system data processing conformity with the law and algorithms of procedures, it is possible rationally to create flexible and effective transport system specific tasks projects. Many theoretical transport system questions are tied very closely because investigating and summarizing transport technologies peculiarities create them.

There are operational, strategic problems in transport technology, and other types of problems that can't be related to any of these. Each particular task is a certain transportation system data manipulation by the functional data property. Each separate transport mode technological operation can be described by the fields of allowable meanings of incoming and outcoming parameters that are the foundation of a model. Each model, having defined suitable operation limits, has to describe a certain part of factors that influence the certain system. The use of a computer becomes a very important factor when there is a big amount of processing information. Informational technologies combine computers, connecting systems, data and knowledge basis [1].

The application of informational technologies allows to solve freight forwarding, loading terminals, "traffic jams" places, loading-unloading mechanisms overuse, predicting, the dynamic of amount of freight according to transport branches and other tasks. Informational technologies are used to maintain the certain amount of stock, for increasing the effectiveness and work efficiency in transport. With the growing number of orders for freight, a necessity for using high standard informational technologies occurred, which are the basis for the creation of a complicated informational system. The following examples can be offered: 
- computerized regulation system for transport orders;

- passenger service information system (passenger registration, automated issue of tickets as well as reservation of seating places, luggage processing improvement);

- transported cargo operational managing automated system (railway transport);

- automated managing system of the railway distribution station, etc.

Storing data in database allows also solving the imitation tasks, by creating and adding to the database artificial transport system units. Therefore, looking at the transport system future, it can be predicted, where new roads, terminals will be needed and where it is a place for disturbances.

Because of the present transport development strategy it is necessary to combine all the forwarding types into a united transport network that is carried out through the mutual connection of freight and rransporting regions. Freight forwarding analysis system includes vehicles, their routes with the evaluation of loading, freight flows and freight traction stations. The problems of how to use transport in the most effective way are also studied [2-4].

Fig 1 shows an informational supply system of the transport system strategy that can directly influence the development of the transport system in the whole country.
The tasks shown are used to be the fundamental basis, which allows creating new tasks, to form and to solve them using data modeling mechanisms.

\section{Basic Data Structures of Technological Tasks}

The state and regional transport could be understood as a multi-criteria system. In such case the accepted solutions are not compared by any property, but all the criteria are evaluated. It is complicated to evaluate all transport modes at once. Recently multi-factorial analysis methods have become the most popular and widely spread. These methods are best suitable for highways, transport corridors defining the main state cities as well as for the identification of the Europe region routes.

Information about freight forwarding within transportation technological process should be transferred by the certain data structures to the places of destination of transported freight and passengers.

The transportation data and transportation informational tasks system features can be distinguished. The data is divided into four basic groups. This is data about:

- vehicles;

- transportation region together with the transport object disposition;

- transportation process participants;

- freight (goods).

This data is divided into the following logical data

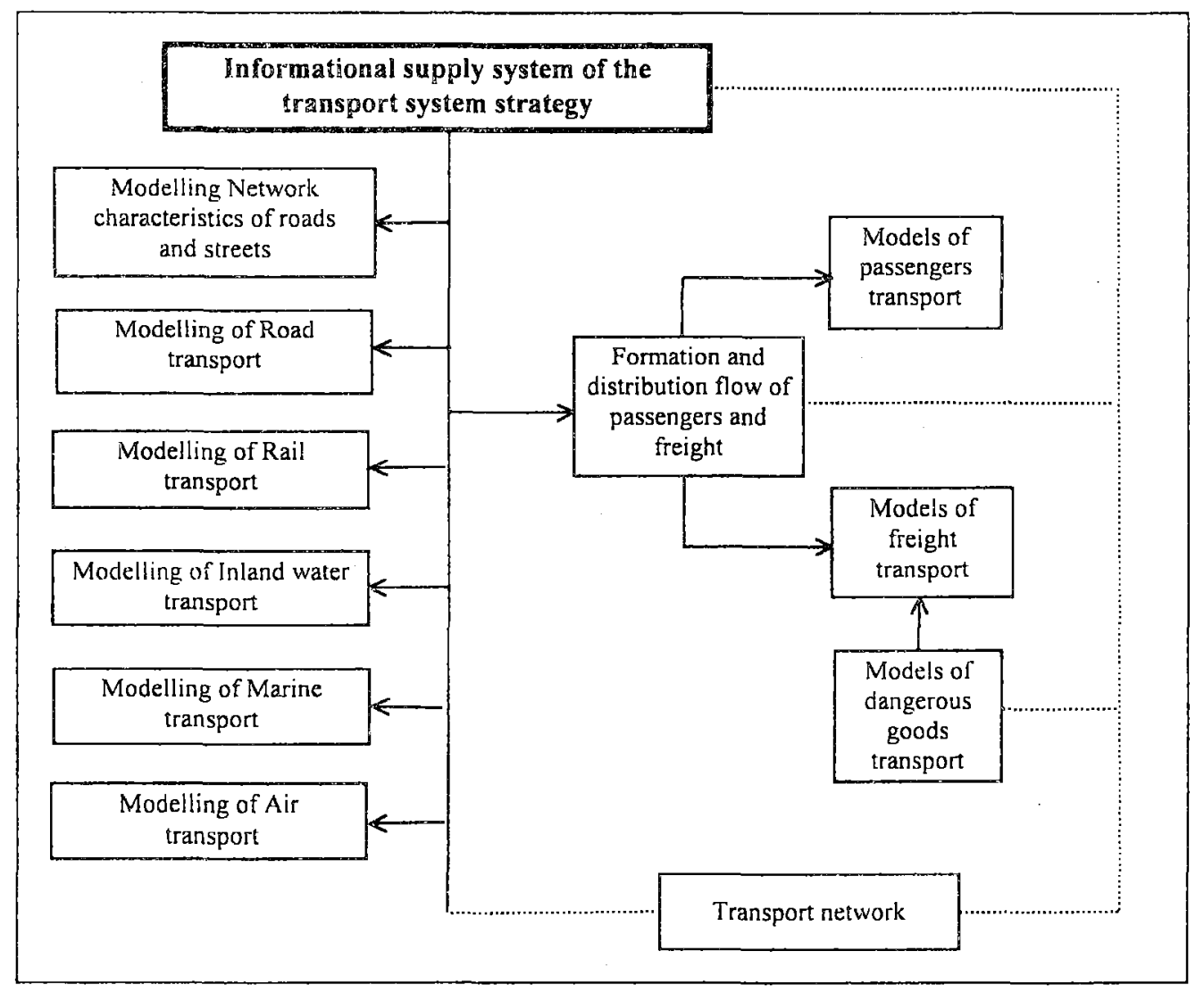

Fig 1. Informational supply system scheme of the transport system strategy 
accumulations, which allow repeating of certain data structure in it:

- consignor's database;

- consignee's database;

- forwarder's database;

- transport vehicle owner's database;

- archive database;

- central transportation database (local and international level) (Fig 2).

Such distribution as well as its realization level depends on transport informational network realization level. Informational transport network has to provide the information exchange for the basic transport process participants (forwarders, vehicle owners, regular consignors-consignees) between themselves and the center database. Information about consignment has to considerably outstrip the consignment itself. Data accumulation allows grouping the transportation information basic processing goals.

For the following formal transport technology development it is important to define the data precisely by its forming stages, structures as well as the data features itself. It is necessary that we could recognize the data at any manipulation stage, point or cycle. Such recognition is made using identifications and creating identification system by the certain methods.

\section{Usage of Identifications for Search}

Information about freight forwarding is divided into structured and non-structured. Non-structured information consists of various files in a text format. Most frequently they are created by MS Word and make $70 \%$ from all the computerized form of information existing in the enterprise [5]. E-mail and fax documents which enterprises exchange with each other make a big part of nonstructured data as well. On the other hand, the amount of structured information is also increasing. There are different databases.

To find information faster all the computerized search programs use indexation of overlooked data. Indexation is a summary of information key words.

The key word or text constant-request makes the search in the index file. This request is compared with the titles of index files and the request and title conformities are submitted. This method is right when there is no big number of such conformities. Otherwise, the problem of finding the necessary information occurs again. The logic search possibility helps to decrease the requested amount of information. It allows to use logic operators AND, OR, NOT. Moreover, many of the present search programs provide additional search possibilities: special symbols, relative search, intuition search, suitability category.

\section{Modelling of Formal Data Collection Structures}

In particular cases, when there are certain regulations for any (for example, dangerous) forwarding, it is necessary to model them up to such a level, that they wouldn't have exceptions, references to other regulations, special cases, etc. This is the only possible way to use formal computer methods collecting necessary regulations for certain freight forwarding [6]. Therefore, it is needed to form general regulations basis for forwarding cargo and its amount, to separate freight forwarding and the formation and change of regulations of its properties in database from ever-changing software conventionality.

\subsection{Methods of Modelling Regulations}

There are several methods of modelling freight forwarding regulations. All of them are connected with the basic method, which is a called horizontal and vertical hierarchy method [7]. It means that, at the highest hierarchy level materials identification number (or consignment code number) and name are taken.

At this level the inverse data distribution is concerned to be fully identical: consignment (material) name and

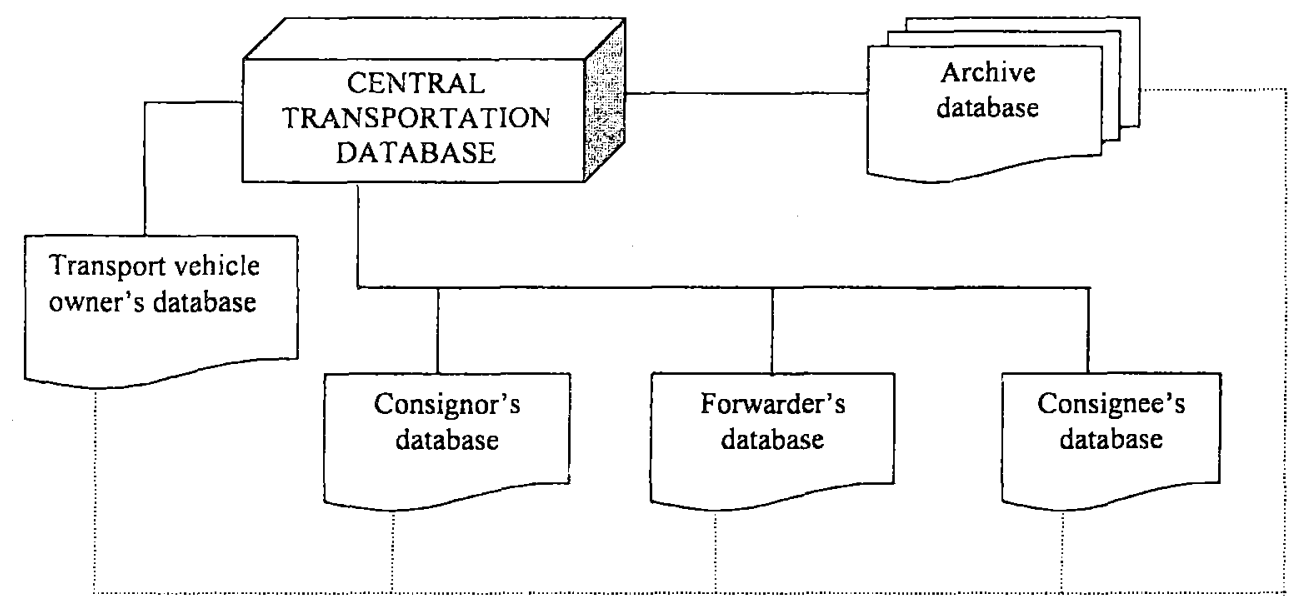

Fig 2. Logical data accumulation structure 
identification number (consignment code number). The latter data is concerned to be not only the beginning of the hierarchy, but the basic object, which is characterized by other regulations.

Scheme of sorting data by various criteria is shown in Fig 3.

$A$ and $B$ elements can exchange their places and be sorted. Such an exchange is used very often in practice. $k_{1} \ldots k_{i} \ldots k_{n}, k_{i 1} \ldots k_{1 n}$ show regulation names and codes, which directly characterize a certain material, notifying various requirements, such as, how to transport goods, how to package them, with what materials to package, what is the maximum amount, allowed to be transported, etc.

Sorting data by various criteria the certain way of criteria distribution allows to direct transport technology projecting to a certain direction that results in the meaning of the project. Changing the way of criteria distribution we would have a new transport technology project. It is permitted to fill in the new data, to change the part of the present data or to remove its part at all. It can be done without any change of formal system meaning.

\subsection{The Codification System of Dangerous Goods Transportation Regulations}

To prepare dangerous goods transportation regulations (ADR and RID) search program it is necessary to restructure all the regulations and subinit corresponding indexes and codes to the most important ones. Three basic data groups can be distinguished in dangerous goods transportation regulations:

- Basic data, common for most cargo. It is marked as $\mathrm{B}^{* * *}$;

- Informational data, marked as $\mathrm{INF}^{*}$ *;

- Special purpose (special) data used while transporting certain class cargo only. This is marked as SP*.* The first "*" sign defines class number of the dangerous material and for whom these regulations are made. After dot there follows row numbers of regulation groups.
Letter " $\mathrm{B}$ " codes basic data and the number near it means the name of the regulation group.

\section{Example:}

- B0 - danger identification number;

- B1-limiting coefficient of the amount of transported dangerous fright, multiplied by the amount of transported freight. It should not exceed 1000 number (or amount is unlimited);

- $\mathrm{B} 2$ - danger signs;

- $B 3$ - type of package, etc.

Informational regulations have the following property. It is very difficult to refer them to a certain dangerous material in advance. That is because most materials are suitable for these regulations if the material type is suitable for the construction of a package or vehicle.

Types of informational regulations:

- INF 1 - average capacity containers;

- INF 2 - requirement for IBC containers;

- $\quad$.

- INF 7 - regulations for tank containers;

- $\quad \ldots$

- INF 9 - type of forwarding, etc.

- $\quad$.

The data about transport vehicles has an important place in the informational regulations list of coding system

- INF 10.1 - types of vehicles;

- INF 10.2 - electrical equipment;

- INF 10.3 - means for fighting a fire, etc.

Special purpose regulations are applied for a certain class of dangerous material. For example:

- $\quad \mathrm{SP2}$.1 - $\quad$ state position of the 2 nd class dangerous materials and products;

- SP2.2 - $\quad$ danger groups of the 2nd class dangerous materials and products;

- $\quad$.

- SP3.4 - unsuitability for transportation 3rd dangerous class materials together;

- SP3.5 - special packing regulations of the 3rd class dangerous materials.

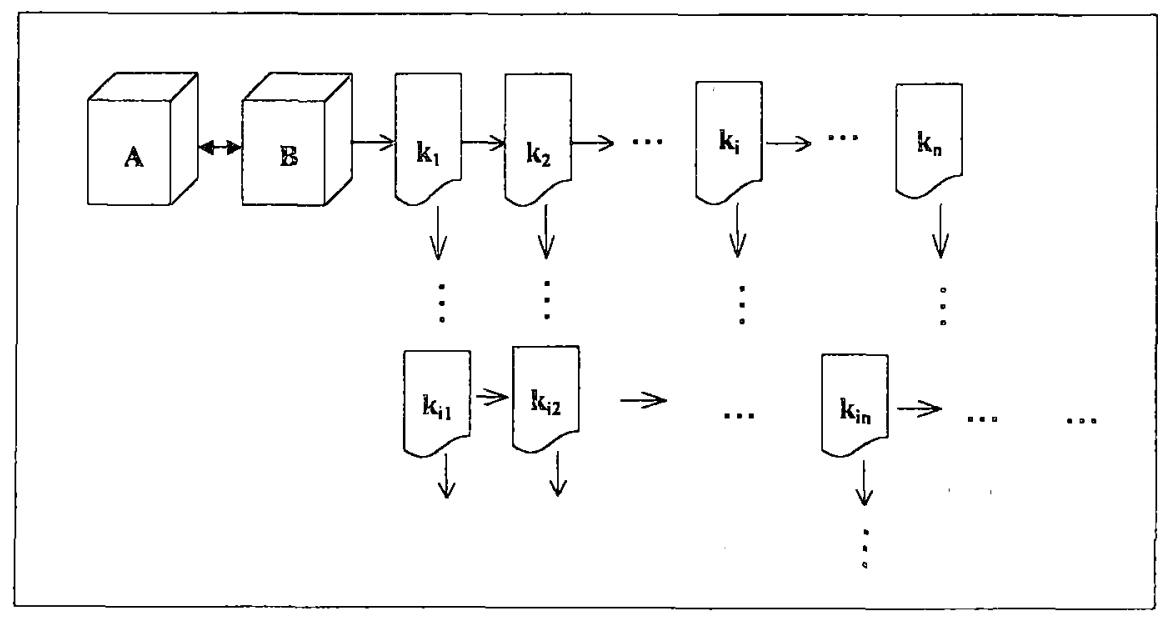

Fig 3. Scheme of sorting data by various criteria 
The basic regulations submitted to the list of dangerous materials prepared in advance and intended for transportation of a particular cargo are: general, informational and special purpose regulations.

If the name of the dangerous material or ITO supplied identification number is known, it is possible to find the required regulations for forwarding this particular material. With the help of a computer by the code system formed it is possible to choose the main requirements which are applied for the transportation of one or another freight. In this way it is possible to create basic regulation models for all hazard materials for all the dangerous freight-forwarding participants [8].

Using given codes a computer helps easily to find the basic regulations required for the transportation of certain kinds of materials.

\section{Search and Presenting Programs}

I will describe both search and presenting programs which work in the Windows environment and consider the information differently. They realize search possibilities offered before.

First of all it is a program packet AskSam. It represents the information search and regulating program group. To use it all the necessary information to be examined should be imported into the general text database, first. This program is intended for a user, who operates large amounts of information produced from various text information or e-mail. It makes available to import not only the files of various formats, but also provides possibility for entering both non-structured and structured information using fields.

Entering information and different formatting commands is similar to working with the MS Word program. Indexation is automatic. Moreover a user may create text references to certain documents, its fragments or Internet addresses. Logic, relative and intuition search is available. The AskSam search program can provide search results as a separate, satisfying the request conditions, set of documents. Anyway there is a possibility to get a list, containing the only paragraphs and sentences satisfying the request. If the document is structured, the report is provided only according to the fields indicated.

The program packet Folio Views allows similar possibilities. This packet is more suitable for the users, working in the network and using multi-users databases.

Another example of informational search program is ISYS Electronic publisher. This is a program providing work with data in its initial format. There is a possibility to review the documents, to replenish files with the comments, references or graphics. Similar as in AskSam program it is available to make logic, relative or intuition search as well as to use special symbols. ISYS acts as a word mill, which allows forming the request right from the headings of the index files. The disadvantage of the packet is that the requests can be formed only in the English language.

\section{Conclusions}

1. Informational - technological modelling turns the continuous freight forwarding process unity to the informational system object.

2. Informational technologies allow influencing the development of the transportation process as well as its directions and the motivation of the most important tasks.

3 . The informational transport network has to provide the automated change of information for all the forwarding process participants.

4. The data criteria distribution order defines the transport technological projects.

5. The data differentiation allows performing the automated search.

6. The created model system in transport not only causes the acceptation of transport development methodics, but also replenishes it with new aspects.

7. Improving the informational technologies application strategy it is required to improve the passenger and freight transportation models in such a way as to make it possible to characterize the transportation distribution among the separate transport modes.

\section{References}

1. McNurlin, Barbara C.; Spreague, Ralph H. Information system management in practice. New Jersey, Prentice Hall, Inc. Englewood Cliffs, 1989. 198 p.

2. Guelat, J.; Florian, M.; Crainic, T.-G. A Multimode Multiproduct Network Assignment Model for Strategic Planning of Freight Flows. Transportation Science, Vol 24, No 1, February 1990, p. 25-39.

3. Newman, Alexandra M.; Yano, Candace Aray. Scheduling Direct and Indirect Trains and Containers in an Intermodal Setting. Transportation Science, Vol 34, No 3, August 2000, p. 256-270.

4. Lewinski, Andrzej; Konopinski, Lech. Computer network systems for railway transport control and management. In: Proceedings of II International Conference Transport systems Telematics TST'02, Vol II, October 9-11, 2002, p. 186-190.

5. Levene, A. A.; Mullery, G. P. An Investigation of Requirement Specification Languages: Theory and Practice. Computer, May 1982, p. 50-59.

6. Adomènas, P. G. Structural modelling of international regulations of dangerous goods carriage by road (ADR). Transport Engineering (Transportas), 1997, 2 (15), 1997, p. 4-8 (in Lithuanian).

7. Batarlienè, N. Hierarchies of regulations of dangerous goods carriage. Transport Engineering (Transportas), 1999, Vol XIV, No 2, p. 51-54 (in Lithuanian).

8. Adomenas, P. G.; Batarliené, N.; Galkauskaitè, J. Information modelling of dangerous freight transportation regulations for database management systems (DBMS). Transport Engineering (Transportas), Vol XIV, No 6, 2000, p. 261264 (in Lithuanian). 